\title{
Existing Problems of University Student Work and the Countermeasures
}

\author{
Haiyang Wu, Sisi Dai and Yanli Zhao \\ College of Music ,Jiangxi University of Technology
}

Keyword: University; Student Work; Problem; Countermeasure.

\begin{abstract}
Along with the higher education of China entering a period of popularization, the internal and external environment for universities has changed greatly. The student work in universities gets many new circumstances and problems, students' thoughts and ideas changes as well; consequently, traditional ystem and methods for student work now cannot suit the new situation and there is a need to pursue effective countermeasures to suit students' development. It is an important subject for university at present to resolve that how university student work shall resolve existing problems efficiently. This paper identifies education, management and service and links between these and students by elaborating the inception of student work.
\end{abstract}

\section{Introduction}

Chinese higher education entered into the period of popularization with its gross enrollment rate increased significantly since university enrollment expanded in 1999. According to data stated by Education Ministry, general colleges in our country enrolled 5.4 million students totally in 2006 with a $22 \%$ gross rate and numbers of attending students in total were 25 million which ranked first in the world, while the gross enrollment rate would upgrade to about $25 \%$ in "Eleventh Five-Year" period. Along with the transition period of entering WTO is coming to an end, the pace marketizaion and internationalization of the higher education is gradually accelerated, and all aspects of it begin to run business accordingly with market needs which means students begin to pay for their study, relations between students and schools changes, students' self-consciousness is further strengthened, and so meeting the needs and development of students become more important for universities. Along with rapid development of modern high technology and the intensification of the trend of global economic globalization, the monopoly of higher education market and resources will be thoroughly broken which bring challenges and opportunities for our higher education. It has become the core issue of universities that how to quickly adapt the needs of the situation, make quick adjustment and transformation accordingly in aspects as teaching method, students' education and management, subjects building and research innovation and to teach students into high-quality talents with international view and creative ability. Traditional student working mode takes a great challenge and the multiple spread of ideological and cultural brings work for students with more difficult.

In Higher Education Act, it clearly state about the task of higher education is to "foster senior specialized personnel with innovative spirit and practical ability, develop culture of science and technology, and enhance the building of socialist modernization". While for student work, it almost takes all functions of students' extracurricular education, management and service, and it is one of the important parts for fulfilling the goal of college talents' training. University student work plays an important role in "training university students into qualified builders and reliable successors of socialist cause", and has an irreplaceable position in revolution and development of higher education. 
Under the new situation, many new circumstances and problems take place for university student work and students' thought and idea have great changes. The traditional student working system and method cannot suit the new situation, so it needs to positively pursue effective countermeasure in order to contribute on fostering talents. And how to solve the new problem with effective countermeasure for the work is an important subject that shall be addressed in present. All universities are continuously trying to research, explore and practice the revolution and creation of university student work. It has clearly stated in CPC Central Committee and State Council on Further Strengthening and Improving Ideological and Political Education that political education shall be run through in the process of university education, management and service, and that the combination between education and management shall be insisted to form a effective system for university students' political education, and that students' manage approach, methods and tools shall be researched and innovated. Therefore, it is presently the most important problem which needs to be researched and discussed whether from theoretical or practical point of view. By choosing student work as the subject, the author as a student worker, can not only summarizes experiences and lessons from the work but also makes further theoretical study on it, and which is very meaningful for upgrading knowledge of student work and directing actual work.

University student work in foreign countries has many characteristics like mature theories, wide-ranging content, clear responsibility, concentration on efficiency and quality and professional management, etc.:

1 , mature theories

2, wide-ranging content

3 , clear responsibility

4 , concentration on efficiency and quality

5 , professional management

6, professional management responsibility

Although situations of universities in different foreign countries is not the same, the main point of student work and management is different and their specific goal is neither distinct, they have the same trend that enhancing the development of professionalization of student management for students' learning and personal development. Meanwhile, theory of students' development is gradually becoming as the basic directive theory of university student work in Europe and America.

This paper mainly takes a research on problems and countermeasures of university student work. Firstly, it will locate the functions of university student work and define the meaning and scope to distinguish it from university teaching and other works. Secondly, it will also demonstrate that students' development shall be the corn purpose of student work through analyzing the relation between the three functions and students' development. Otherwise on this basis and in aspect of problems existing now in university student work, it will summarize and analyze the realities and reasons for the working system, working method and professional development and further refine about the new concept to improve student work. Then, under the direction of the new concept and around student development, it will pursue effective countermeasures to deal with inner relations among education, management, and service in a good way, and to make education, management, and service fuse and penetrate into the system, method and service of student work. 


\section{Positioning of university student work}

As a conventional customary term, university student work has a dynamic character that has different meanings in different periods. It is a category concept, a general term of working range and a collective of conceptions, matters and actives for non-academic education, management and service taken by students. It customarily has a corresponding function department named Student Affairs (Department) in which not all functions of student work actually it is included. It is interesting that normative documents and authoritative book for students in higher education has never define student work, but has formulated responsibilities for counselors who work for student work. Student work has been permeated with the development of new higher education in China, and with the growing political, economic and cultural, it continually made dramatically changes. College student work in China originated in the political work of student, and the main task of it is to guide the students learning politics and political activities. In the first 17 years after the Founding, students work had no independent status, but only presented as part of political work for school. In recent years, as China's economic, political and social development of the macro background changing rapidly, deepening the reform of higher education, university student work has undergone great changes, the content of student work begins to tend to emphasize the ideological and political and to focus on the combination of students' ideological and political education and affairs administration. The duty ranges of it is continuously expanded, and a series of unprecedented long-neglected student affairs becomes particularly noticeable, such as student psychological counseling, student aid, work-study, graduate employment guidance and so on. Students work gradually gets broader meanings, excepting to emphasize education, control, governing and regulating the function of the students, but also begin to emphasize the functions of guiding and service students. In our country, two typical terminologies from American higher education like "student services" and "student affairs" begins to be used in the field of student work in our country.

Although, the term "Student Work" is increasingly being used, the definition about it is ambiguous in sight. In the book "College Student Working Standards and Guidance," Zhihong Hu said: "Students work were works of education, management and services that directly effect on students and develop and improve students of political, ideological, moral, psychological, personality qualities and guide students with correct behavior in purposeful, planned and organized ways taken by the specialized agencies and personnel". While Zhao Ping, the former deputy party secretary of Beijing University of Aeronautics and Astronautics, translated "Student Affairs" and "Student Services" from United States into paraphrase "student work". He said: "student affairs and student services from the United States have similar objects, nature, content and scope with Chinese university student work which so was generally used to represent student affairs and management on these affairs. Same as American student affairs and management of it, it stood for a collection of all the concepts, issues and activities related to non-academic affairs and student extracurricular activities". In view of the extension of student work is too large, functions of Student Work Department defined by many colleges and universities emerge discrepancies, the students work system gradually become an integrated one of education, management, consulting, recruitment, employment, financing, societies building, social practice, and campus culture constructions, and showed a tendency to expand.

In the 16th file stated by CPC Central Committee and State Council on August 6, 2004, it profoundly expounded from the perspective of era, strategic and overall about the extreme importance and urgency, called for strengthening and improving ideological and political education of college students, clearly put forward the guiding ideology, important principles and main tasks of 
work. On Jan. 17th to 18th, 2005, the Central Committee held a national conference about strengthening and improving university students' ideological and political education. The Ministry of Education issued the "University Counselors Requirements" in May 20th 2006, and in July 30th published the "2006 - 2010 Colleges and Universities Counselor Training Program". As the government issued a series of related policies and regulations, college student work that set education, management and services in one, also ushered in the best and most effective development opportunities and government support. University student work carries with Chinese characteristics bears a broader meaning and a more difficult mission than student affairs administration of other countries with developed higher education. Student work is a variety of education, management and service activities or projects taken by colleges according to national education policies and the training objectives, aims and planning of school. Combined with growing regularity and characteristics of students, the activities is well-designed, organized and implemented to give influence and promotion on the formation of student values, the intellectual growth, the ability enhancement, the emotion training and other aspects of growth.

(A), Education: The object of student work is college students, and one of the basic functions is to educate students. The influences of education and teaching mentioned in student work and the one of curriculum to student's academic have significant differences. Student work is to set a good atmosphere for students' growth and talent, and to promote the development of students in social, occupational, emotional, moral, spiritual and other aspects, so as to fulfill university's mission on training talented people. It mainly focuses on the guiding of ideology and behavior of students and helps students to set a good outlook on life and values and improve their quality at the crucial moment of taught. The way to guide ideology is a very critical aspect in the education process, and a proper way may make more with less. It needs to maintain regular communications with students and give them ideological influences, so as to make them have a strong pursuit of progress subjectively. Generally, the education for student work to complete includes ideological and political education, professional ideological education, health education, safety education, caucus education, education and training on organization and coordination, training of students' interests and hobbies and so no.

(B), Management: Student Work sets education, management and service as trinity and so management is also one of the functions. Management generally means the active process implemented by certain person or organization that use the owned rights to coordinate and process resources of human, material, financial and others by taking set measures, and to achieve the desired goal. Today, management is a fundamental activity across all areas of social life, and it more or less affects people's work and life. From a methodological point of view, management is a process which is reflected in the basic functions and activities of student work planning, organizing, directing, and controlling. Student work management contains two levels: one is the "human" management that managements for individual students and student groups formed on the basis of it; the other is the "thing" management that student-related matters management. For management of individual students and groups, attention is set on the adjustment of the "person to person" relationship, which means to help students with physical and mental development and to make them adapt and integrate into school and community life by means of education, motivation, organization, etc. As for student affairs management, attention is set on management of things and affaires and the match of the "affair to person", which stress the importance of standardized management, improve the efficiency and effectiveness of student affairs, so as to serve the students with all kinds of learning and life demand, thereby contributing to its better development. 
(C), Service: In universities, the traditional student services generally limited on the scope of work in the School Support. Starting from late 1990s, connotation of student work in our country emerged a large expansion. In addition to functions of students' education and management, student services function also began to be emphasized, and the so-called service refers to all ancillary supporting measures and means taken to meet student needs and development. Students work creates certain conditions around student learning and growth to solve practical problems in student learning and life, and provides a full range of services with the characteristics and needs of students as the starting and ending point. To service education object means to take student services as the question of meaning of education and management, combine education and management in service, educate and manage in the service, and also to carry out services in education and management. In present, it is main feature of the development of student work that taking students affairs as the basis and putting services into students affairs which has become synonymous with "including student services".

(D), Education, Management, Service and Student Development: Nowadays, with higher education goes into the popularity development stage, groups of college students consequently have had a big change, such as enhancement of subjective consciousness and the increasing diversity of groups' needs and personal thinking and behavior. The subject status of students has been further clarified after college students started to pay for the school. Students were getting used to evaluate works of school including student work in accordance with their legitimate interests rather than manager's commitment. It became an important factor for the school to win trusts and supports from students or not that whether students can get satisfied with their campus environment, learning, communication, mental and developmental needs. This change requires student work must be implemented with the actual needs of overall development of students as the starting point. It is the starting and ending point of all student work that setting students as the center, student development as the goal, and putting education and management into service. The relationship between education, management, services and student development as shown in Fig. 1, education, management and service are the means, they mutually penetrate and blend to each other and two-way interact, and among them, the student development is actually the core objectives.

\section{Main problems and reasons existing in university student work}

The traditional student working model based in dominant ideological and political education and rigid management has been difficult to meet the needs of the community, education and student development. Due to the lack of accurate positioning of the meaning and relationship of college student work, many college student work have emerged a series of cases as weakened educational function, weakened management authority, and low quality of service. The new situation requires college student work to make adaptive changes to correctly deal with the dialectical relationship between education, management and services. Therefore, they shall correctly understand the main problems of university student work and clarify the role played of education, management and service in developing of students, so as to initiatively change their ideas and actively explore new strategies to highlight education, standardized management, and optimization services.

(A), Fragmentation of the leadership system: System refers to the building of leadership system and structure under certain route, principles and policies. It contains the institutional settings, the affiliation, the division of powers, leadership and management principles and the regulations and so on. While, the system of student work is the organizational guarantee to student work carrying out, 
ideological education of college students, administrators and campus services and to train successors of socialism. Education, management and service are originally the three major functions of student work, but the combinational way of them three cause out the fragmented leadership system of student work for the history and philosophy reasons.

(B), Working method with one-sidedly emphasizing on education and management but neglecting on service: "education and management" in student work played positive effects on uniting thinking, instilling socialist ideology and values and maintaining social stability in the process of social development of China. However, many colleges haven't changed their ideas along with the open to and progress of society, long-term stability of our country and the rapid development of higher education. They still hold stereotypical attitudes as "education is to mainly guide students about their ideological, management is to focus on constraining and controlling students' behavior, and service is to solve problems of students' eat and live". Consciousness decides concept, and ideas guide the practice. For it is originated from political work, the university students work has been actually permeated with the traditional political ideas in all fields. The current system of college student work mostly inherits from the old "management" system of planned economy era, schools are active educators and administrators, while students are passive educated and administrated with no subject Status. Working method with one-sidedly emphasizing on education and management but neglecting on service is exactly the profound reflection of the traditional concept. This indicates that the dominant idea of student work lags behind the development of practice.

(C), Lack of professional development: With the development of society, more and more occupations enters into the professional field, and specialization becomes an important trend in social occupation development. Differentiation of educational structure separates student work from teaching and which promote the relative independence of the work. Professional student work is the result of more refined modern social division and higher specialization, is the requirement for higher education development itself, and also is the inevitable trend of development of market economy. The work commits to the full development of students which is at least incomplete if without professional education, management and service. Only when student work adapt to the requirements of comprehensive development of students, can it have its place, so specialization is the inevitable choice of it. Specialization is the requirements of deepening student needs. Facing with these needs, it is difficult to implement the goal of training round developing persons without professional working skills, and as well, the value of student work gets embodied through professional services. Specialization of student work is a continuously process in which professional quality and professionalism of student work get improved. In accordance with accepted professional standards of social, specialization degree of student work in our country is relatively backward especially the lack of professional development. Professional development refers to the process of constant update, evolution and enrichment of the internal professional structure. The internal professional structure includes professional mental consciousness, professional knowledge capability and professional theory and so on. Lack of professional development for university student work refers to obvious deficiency in aspects of professional mental consciousness, professional knowledge capability and professional theory.

\section{Countermeasures to Improve University Student Work}

The problems stated above inevitably exist because the ethic and mode of student work is not able to adapt to changes in the new situation, and the deep-seated reason for these problems is the 
restriction from dominant philosophy. Therefore, only if seek countermeasures starting with leading system, working mode an professional development on the basis of resolving problems of concept, the university student work can be effectively improved, relations between education, management and service can be rationalized, and to create good environment and conditions for the overall development of students.

Updating the concept of university student work: Education, management and service are the three functions of student work, but in a new period, the combinational way of these three functions and the connotations of themselves have the problem of concept creation. In tradition, there more or less exists a conception to take management as main aspect and weak functions of education and service because of which the working level remained at a lower level that not match with the psychological characteristics of young college students and their growth and developmental regularity. The idea update of college student work hall be changed with education, management and service as the starting point. This means: education is to guide students' future development, stimulate students' enthusiasm and internalize it into students' needs; management is to respect students' legal rights, encourage students to fulfill their obligations in accordance with law and expand students' participation; service is to meet students' actual needs, create favorable conditions for the students' growth, and optimize hardware and software environment on campus to address the students' practical problems. Thought is a precursor. To improve and make innovation on student work, the idea must be firstly updated, conceptions shall be conversed and then release from the traditional working mode, liberate from the anachronistic concept of education, and freed from the rigid work ethic, and establish people-oriented work ethic.

Establish student work system with students' development as the core and education, management and service as the trinity: It is the key to resolve existing problems of student work that build a working model which adapts to students' development and consist with talents' training and education regularity under the direction of correct conceptions. Quality of talents' training is deeply constrained by training mode of it which meanwhile is influenced by social policy, economy, culture and personality of educated in combined. In order to meet the social development, the construction of university talent training mode, must timely adjust the disciplines and talents' training specifications and objectives always on the basis of the needs of social development; must timely adjust the training program with capacity to nature and innovation as the basis. About disciplines and training programs, it mainly relates to teaching, research in the field, and so is not a study scope of the student work. The mission to create good environment for students' growth and talent to promote students' development and further to serve on university talents' training is the core point of student work. Wen Jiabao said during his visit to students of Bejing Normal University at the Youth Day of year 2007 that "We emphasized people-oriented, in school it is to be student-centered". In consequence, it is the inevitable choice for sustainable and coordinated development of student work that to build a working model which adapts to students' development and make education, management and service as the trinity by setting student as the center point, firmly establishing the concept of student service, and revolving around the needs students.

Improve the way of working: Work method is an important part in process of achieving goals, no matter how perfect the working system is or how rich the content is, it shall be implemented under certain way. Consequently, improving working methods must be one part for countermeasures of overall student work, which includes working procedures, working methods, and work attitude and so on. 
Improve professional development: Because the time or other resources to each person or organization is not infinite, it is impossible to be outstanding in any field or any of several fields. So specialization is the inevitable choice to have success. Specialization of student work have the relatively independent status of student work and its management in higher education, the in jobs of institution professionalism specially set up and the professional management personnel as its symbols. Comparing with development of student affair's specialization in western countries, the one in our country is a gradual long-term developing process; slow development of it has become the bottleneck of innovation in this field. In conclusion, accelerating the professional development of student work is the basic requirement of specialized construction.

\section{Conclusions}

The revolutions and development of the higher education itself and factors of education and culture brought by economic globalization are profoundly affecting all aspects of university student work. College student work must proactively adapt to the requirements of higher education reform and development to establish new philosophy to serve for fulfilling of overall development of university student work and complying with higher education revolution as the ultimate goal. Round development of students is a matter of student work and concerns for other educators; this understanding is the basis of student work, and also a new model basis for establishment of student work. It is the fundamental countermeasure for resolving problems exist in university student works that to respect students' legitimate rights, guide students' development and to serve their needs.

\section{Reference}

[1] Cai Guochun, Definition for College Student Work Conception, [J] Yangzhou University Journal (Higher Education Study Edition), 2rd phase of 2000.

[2] Cai Guochun, Conception Change of University Student Work in 21st Century, [J] Jilin Education Science (Higher Education Study Edition), 1st phase of 2001.

[3] Ji Xuefeng, Discussion on Model of University Student Work in New Era, [J] Education Science Journal of Hunan Normal University, 3rd phase of 2005.

[4]Wu Zhigong, Liang Jiafeng, Discussion and Analysis of Modern University Students' Work, [J] Forum on Contemporary Education, 7th phase of 2004.

[5]Wu Zhigong, Liang Jiafeng, Xu Lei, Contemporary Chinese College Students Work Dilemma and Way Out, [J] Forum on Contemporary Education, 3rd phase of 2006.

[6] Liu Peihuan, Li Wangping, Decade' Review and Reflection in Research on University Student Work, [J] Forum on Contemporary Education, 3rd phase of 2006.

[7]Shen Wei, Study on Developmental Mode of Student Work in University, [J] Beijing Education (Higher Education Study Edition), 4th phase of 2007.

[8] Zhang Haoming, Revolution and Development of University Student Affairs Management, [J] Chinese Higher Education, 21st phase of 2005. 
[9] Ma Haiquan, Lv Dongwei, Imperative to Innovate University Student Management--Interview with Relative Department Heads of Ministry of Education Student Division, [J] Chinese Higher Education, 8th phase of 2004.

[10]Wang Duo, An Unforgettable Field - Promoting College Student Affairs, [J] Study on Science and Technology University, 1st phase of 2004. 